\title{
Über Abort oder Fehlgeburt nach indischen Bewertungen
}

\author{
Von Reinhold F.G. MüLLER †
}

Robert Herrlinger hatte die Fragen zur «Geschichte der medizinischen Indikation des Abortus arteficialis» im Deutschen Ärzteblatt, Heft 45 (1963) aufgeworfen, wonach «die Diskussion, die sich seinerzeit entwickelt hatte, abgeschlossen » galt, obwohl dort Heft 45 (1964) Liselotte Buchнeim dazu ägyptische Bezüge darlegte und zu weiteren Untersuchungen anregte. Nachfolgende kurze Darlegungen betreffen somit indische Vorgänge.

Die alte Oberschicht der Inder leitete ihre Herkunft von Stämmen ab, welche sich selbst «Arier» nannte, wie auch die Perser und Meder ${ }^{1}$. Die Bezeichnung «arisch entspricht einer sprachwissenschaftlichen Beurteilung, welche «seit dem 18./17. Jahrhundert n.Zw. bei den Ariern von Mitanni» in Kleinasien nachgewiesen ist ${ }^{2}$. Diese dürften bei der Einwanderung der Stämme nach Indien beteiligt gewesen sein, welche nach grober Schätzung um die Jahrtausendwende v. Zw. zu setzen ist. Auf diesen Vorgang beziehen sich die Lieder vom Rigveda, welche als die ältesten Texte gelten, welche sich vorzüglich mit Bitten an die Götter richten, so daß sie als «Die Religion des Veda ${ }^{3}$ angesprochen wurden. Jedoch bei dem dehnbaren Begriff von «Religion» ist wenigstens für eine medizingeschlichtliche Rücksicht eine «Welt- und Lebensanschauung» gesicherter ${ }^{4}$.

Die Rigveda-Lieder sind durchsetzt vom Wunsch nach einem langen Leben, der wie ein Titel in die ärztliche Wissenschaft der Inder übernommen wurde ${ }^{5}$. An diesen Wunsch schloß sich oft und eng das Begehren um Nachkommenschaft an, so etwa in der Bitte an den Feuergott in V,4,10: "Durch Kinder möchte ich Unsterblichkeit erlangen ». Die Hoffnung, nach dem Tode in dieser Weise weiter zu leben, konnte eine U̇bernahme der sogenannten Seelenwanderung ${ }^{6}$ begünstigen, welche nicht als ursprünglich arisch zu beurteilen ist. Als wesentlich tragende Grundlage blieb das Streben nach Fortpflanzung erkennbar.

Dazu bietet schon Aitareya-Brähmaña ${ }^{7}$ Besonderheiten von der Geburt von Kindern: «Von allen Freuden - ist des Vaters Freud' am Sohn die größte», hingegen «ein Jammer die Tochter» - «Da alle Menschen einen Sohn sich wün-

1 Weissbach, Z. dtsch. morgenländ. Ges. 90 (1936) 41.

2 Hausschild, Über die frühesten Arier im alten Orient, Berlin 1962; vgl. auch MaYrhoFer, Z. dtsch. Morgenländ. Ges. 111 (1962) 451-458.

3 Oldenberg, Die Religion des Veda, Berlin 1891.

4 Asia Major, Leipzig 1930, Vol. 6, S. 315-387.

5 Mitt. Inst. Orientforsch. (Berlin) 8 (1961) S. 83, Nr. 36.

6 Hastings Encyclopaedia of Religion and Ethics 11, (1920) 725-755; 12 (1921) 425-441.

7 Text von Aufrecht, Bonn 1879, S. 195 f. 
schen.$^{8}$ Der «Wunsch nach einem Sohn» (putra-käma) bildete auch den Titel zum ersten Abschnitt der Embryologie in der Zusammenfassung durch Vägbhața ${ }^{9}$. Die Bedeutung vom Fachausdruck napumsaka = nicht männlich oder dergleichen, meist als «Zwitter» unterstellt, betont die Einschätzung des männlichen Kindes ${ }^{10}$, die aber doch Bewertung von Nachkommenschaft allgemein einschließt.

Die Entbindungshilfe war durch die indischen Wundärzte sehr entwickelt. Bei den acht Einstellungen des durch den austreibenden Wind «verirrten» Kindes (uterus und seine Muskelfunktionen war indisch unbekannt) wurde nur in zwei als unheilbar geltenden Fällen das Kind mit dem Messer zerstückelt ${ }^{11}$, dessen Leben sonst bewahrt bleiben sollte. Deswegen war der «Kaiserschnitt» nur bei einer bereits verstorbenen Mutter zulässig ${ }^{12}$. Das « verirrte» Kind erscheint oft mit der Bezeichnung «tot» ausgetauscht ${ }^{13}$, weil es als śalya $=$ Pfeil $\sim$ Fremdkörper dann galt, so daß auch darnach der helfende Arzt Pfeilzieher (śalyahartar) genannt wurde, etwa bei einem spontanen Abort ${ }^{14}$. Aber ein "Abortus artificialis» ist in den ärztlichen Texten der Inder und auch eine Anweisung zu einer derartigen Maßnahme nicht aufzuzeigen.

Der Mangel einer absichtlichen oder prophylaktischen Einleitung eines Abortes durch Ärzte beruht auf durchlaufenden allgemeinen Vorstellungen, nach welchen Abtreibungen verboten waren. So wurde schon im Arthaśastra von Kautalya eine schwangere Mörderin erst einen Monat nach ihrer Entbindung durch Ertränken bestraft, wobei die Erhaltung des Lebens des Kindes bezeugt erscheint. Beabsichtigte Abtreibungen wurden unverzüglich geahndet ${ }^{15}$. In den Gesetzen von Manu sind zweimal (V,90, X,88) Strafen wegen Unterbrechung der Schwangerschaft vermerkt, ebenso in anderen gesetzlichen Anweisungen ${ }^{16}$.

Die indisch-eigenartig ausgebildeten Lehren über Erotik erwähnen «Mittel, die ausgebliebene Menstruation wieder in Ordnung zu bringen», und deuten damit auch solche «zur Herbeiführung eines Abortes» an ${ }^{17}$. Daher konnte sogar ein unverheiratetes Mädchen nicht als der «Embryotötung schuldig» gelten ${ }^{18}$, jedoch

8 Winternitz, Geschichte der indischen Litteratur, Leipzig 1909, Band 1, S. 184.

9 Mitt. Inst. Orientforsch. (Berlin) 8 (1963) 409-424, zumal 418.

10 Phema, München 1961, Heft 7, S. 3-23.

11 Arch. Gesch. Med. (Leipzig) 30 (1928) 238-271; Nova Acta Leopoldina, (Leipzig) N. F. Nr. 138 (1958) 49-52.

12 Grenzgebiet der Medizin (Berlin/München) 1 (1948) 60-62.

13 Jolly, Medizin, Straßburg 1901, S. 64, § 47.

14 Osiris (Brugis) 13 (1958) 380-397, zumal 389, Anm. 35.

15 J.J.MeYER, Das altindische Buch vom Welt- und Staatsleben, Leipzig 1926, S. 312, 355.

16 BüHLER, The Laws of Manu; cf. Synopsis zu anderen Gesetzüberlieferungen, Oxford 1886, S. 577.

17 R.Schmidt, Beiträge zur indischen Erotik, Berlin 1922, S. 640 f., 655.

18 Kritik von Srinisvasan in Orientalische Literaturzeitung (Berlin) 60, (1965) Sp. 279. 
wie eine notbedingte Ausnahme. Denn schon im Atharva-Veda II, 25 ist das Lied als Schutz gegen «Fehlgeburt» auffaßbar ${ }^{19}$ und diese Auffassung von den Wundärzten in Suśruta-Samhitā śärïra ${ }^{0} 10,58 \mathrm{ff} .^{20}$ übernommen.

Auch bei den wenigen ärztlichen Belegen zur vorliegenden Aufgabe waren einige Hinweise als alte und durchlaufende Grundlagen allgemeingültiger Anschauungen indischer Denkweisen nicht vermeidbar und begründeten Berücksichtigung. Sie bezeugen ausgesprochen nach den Regeln eine hohe Beachtung des Lebens, wie sie auch sonst erkennbar ist. So wurden beim Genuß von Wasser Lebewesen, wie Insekten, Würmer oder dergleichen, durch Sieben usw. entfernt, vor allem um diese nicht zu töten. Noch modern weigern sich bekanntlich viele Inder, sich bei gefährlichen Erkrankungen durch Serum behandeln zu lassen, weil zur Bereitung solcher Heilmittel Tiere getötet wurden. Derartige Vorbegründungen sind auch bei der Abneigung gegen einen beabsichtigten Abort anzunehmen, gegensätzlich zu modernen westlichen Maßnahmen, welchen aber auch von anderen, etwa religiösen Voraussetzungen Abhängigkeit zeigen. Zu letzteren kann als ein Muster Der Kardinal $^{21}$ erwähnt werden, welcher eine « Craniotomie» des Kindes seiner Schwester bei ihrer Entbindung ablehnte, so daß diese sterben mußte. Mit diesem Hinweis ist auch eine Grundlage aufgezeigt, die zu derzeitigen Auseinandersetzungen von der Zuverlässigkeit vom «Abortus atreficialis» Anlaß gab.

19 Whitney, Atharva-Veda Samhitā, Harvard Oriental Series Vol. 7, Cambridge (Mass.) 1905.

20 Bhishagratna, Engl. Translat. (Calcutta) 2 (1911) 237.

21 H.M. Robinson, Der Kardinal, Darmstadt 1954. S. 270 ff. 